\title{
Effects of the Phosphorus Content in Ni-P substrate on Properties of Immersion Gold Coatings Obtained from Choline Chloride Solution
}

\author{
Yurong Wang ${ }^{1}$, Xiaoyun Cao ${ }^{2,3}$, Zhiming Wang ${ }^{2, *}$, Zhidong Chen ${ }^{3, *}$, Naotoshi Mitsuzaki $^{4}$ \\ ${ }^{1}$ College of Pharmaceutical Science, Zhejiang Chinese Medical University, Hangzhou 310053, China \\ ${ }^{2}$ School of Pharmaceutical and Chemical Engineering, Taizhou University, Taizhou 318000, China \\ ${ }^{3}$ School of Petrochemical Engineering, Changzhou University, Changzhou 213164, China \\ ${ }^{4}$ Qualtec Co., Ltd, Osaka 590-0906, Japan \\ *E-mail: zhiming@tzc.edu.cn, zdchen@cczu.edu.cn
}

doi: $10.20964 / 2019.08 .12$

Received: 1 April 2019 / Accepted: 20 May 2019 / Published: 30 June 2019

\begin{abstract}
The effects of the phosphorus contents in electroless Ni-P substrates on the morphology, structure and corrosion resistance of gold coatings deposited on Ni-P surfaces, which were applied via a $\mathrm{HAuCl}_{4}-\mathrm{ChCl}$ gold plating solution by galvanic displacement deposition, were investigated. Compared with low contents, high $\mathrm{P}$ content was not only more suitable to achieve bright golden $\mathrm{Au}$ surfaces, but also enabled the Ni-P coating to achieve high corrosion resistance during the immersion gold deposition process in the acidic gold plating solution and for further protection of the $\mathrm{Cu}$ sheet.
\end{abstract}

Keywords: Choline chloride; corrosion; electroless plating; phosphorus content

\section{FULL TEXT}

(C) 2019 The Authors. Published by ESG (www.electrochemsci.org). This article is an open access article distributed under the terms and conditions of the Creative Commons Attribution license (http://creativecommons.org/licenses/by/4.0/). 